\title{
Efecto de diferentes medios y sustratos en el enraizamiento y adaptación de rosa transgénica ${ }^{1}$
}

\section{Effect of different media and rooting substrates on the hardening-off process of transgenic rose}

\author{
Adrián Héctor Palacios-Arriaga ${ }^{2}$, Nutan Prasad Rout ${ }^{2}$
}

1 Recibido: 13 de setiembre, 2017. Aceptado: 25 de junio, 2018. Este trabajo formó parte de trabajo de tesis de licenciatura del primer autor, en el Centro de Investigación y Asistencia en Tecnología y Diseño del Estado de Jalisco, A.C. (CIATEJ), Guadalajara, México.

2 Centro de Investigación y Asistencia en Tecnología y Diseño del Estado de Jalisco, A.C. Av. Normalistas \#800, Colinas de la Normal, Guadalajara, Jalisco, México. ahpa_2601@hotmail.com, nutan@ciatej.mx (autor para correspondencia; https://orcid.org/0000-0002-0271-853X).

\section{Resumen}

Introducción. El cultivo in vitro permite el mejoramiento de Rosa hybrida, no obstante, la sobrevivencia de plántulas es difícil durante la aclimatación en sustrato sólido, el proceso conlleva a que las plantas presenten malfuncionamiento de los estomas y por ende, baja asimilación del dióxido de carbono. Objetivo. El objetivo de esta investigación fue evaluar tres medios de enraizamiento in vitro y diferentes sustratos para la aclimatación ex vitro mediante medios sólidos y líquidos de la rosa transgénica. Materiales y métodos. Se utilizaron plantas de rosa (Rosa hybrida L.) cv. Classy transgénica, a partir de embriones somáticos, cultivadas in vitro durante dos años y se sometieron a enraizamiento in vitro y ex vitro, seguido de aclimatación. Para enraizar in vitro tres medios diferentes y para los experimentos ex vitro, se utilizaron siete combinaciones diferentes de sustratos. El estudio se llevó a cabo de agosto de 2012 a enero de 2013 en el Centro de Investigación y Asistencia de Tecnología y Diseño del Estado de Jalisco, A.C. Resultados. Los resultados de los experimentos in vitro y ex vitro demostraron que los mejores resultados se obtuvieron en el medio MS adicionado con sacarosa (30 g/l) y carbón activado ( $0,5 \mathrm{~g} / \mathrm{l})$, y el sustrato compuesto de turba de musgo (70\%) y perlita (30\%), con $20 \%$ de enraizamiento. El sustrato con $25 \%$ de humus produjo el mayor contenido de clorofila, sin embargo, no hubo enraizamiento. Los tratamientos con sustrato sólido mostraron mayor porcentaje de sobrevivencia de plántulas, alto promedio de hojas por planta, alto contenido de clorofila y buena calidad del brote en comparación con los hidropónicos. La sobrevivencia en estos últimos fue de $40 \%$ sin aireación y $0 \%$ con aireación a los dieciséis días de establecimiento; ambos tratamientos no presentaron enraizamiento. Tratamientos sin aireación no mostraron enraizamiento. Conclusión. Mayores contenidos de materia orgánica en sustrato y la presencia de aireación en una solución hidropónica pueden no garantizar una mayor sobrevivencia durante la aclimatación. Los resultados suponen una optimización en la aclimatación de las plantas y el cultivo hidropónico de rosa.

Palabras clave: Rosa hybrida, medio de cultivo, cultivo sin tierra, aclimatación.

\begin{abstract}
Introduction. In vitro culture allows the genetic improvement of rose (Rosa hybrida), however, the acclimatization of plantlets in solid sustrate is a difficult process, it leads to malfuntion of stomata in the plants and consequently low carbon dioxide assimilation. Objective. The objective of this research was to evaluate three in vitro rooting media and different substrates for ex vitro acclimatization through solid and liquid media of transgenic rose. Materials and methods. transgenic rose (Rosa hybrida L.) cv. Classy plants were obtained from somatic embryo that
\end{abstract}


were cultured in vitro for two years and were subjected rooting in vitro and ex vitro followed by acclimation. For in vitro rooting three different medium and for the ex vitro experiments, seven different combination of substrate were used. The study was carried out between August 2012 to January 2013 in Centro de Investigación y Asistencia de Tecnología y Diseño del Estado Jalisco, A.C. Results. The results from the in vitro and ex vitro experiments showed that the best in vitro rooting medium was the MS medium with the addition of $30 \mathrm{~g} / \mathrm{l}$ sucrose and $0.5 \mathrm{~g} / \mathrm{l}$ activated charcoal. The substrate composed of $70 \%$ peat moss and $30 \%$ pearlite was found to be the best for ex vitro conditions obtaining $20 \%$ of rooting. The substrate with $25 \%$ humus produced the highest chlorophyll content, however, there was no rooting. Solid treatments produced a higher percentage of seedling survival, high average number of leaves per plant, high chlorophyll content and a better sprout quality than hydroponics. However, the survival rate was $40 \%$ in the absence of aeration and $0 \%$ with aeration after sixteen days of the experiment. Treatment without aeration did not show any rooting. Higher contents of organic matter in the rooting substrate and the presence of aeration in a hydroponic solution did not guarantee a greater survival during acclimatization. Conclusion. Higher contents of organic matter in the rooting substrate and the presence of aeration in a hydroponic solution may not guarantee a greater survival during acclimatization. The results represent an optimization in the acclimatization of plants and the establishment of hydroponic culture of rose.

Keywords: Rosa hybrida, culture media, soilless culture, acclimatization.

\section{Introducción}

La rosa (Rosa hybrida) es una de las principales especies ornamentales en el mundo. El cultivo se realiza para tres fines principales: flor de ornato, productos cosméticos y alimenticios. Aparte del uso ornamental, los principales productos son agua de rosa, rosa en conserva y aceite de rosa, los cuales tienen un alto valor en el mercado internacional (Baig et al., 2011).

La demanda en el consumo de rosa ha aumentado y por ello, se requiere incrementar las zonas de producción; así, la superficie mundial de plantas cultivadas y de macetas ascendió a 702400 ha en 2010, de la cual México ocupó el cuarto lugar (Domínguez-Serrano et al., 2016). El establecimiento de estacas llega a ser exitoso en un 60\% en sustrato y dura más de veinticinco días (Cárdenas-Navarro y López-Pérez, 2011). El cultivo de yemas, brotes, callos y nodos son las técnicas más empleadas para la propagación in vitro de las rosas. La optimización de dichas técnicas de cultivo permite producir gran cantidad de plantas enraizadas (hasta un 90\%) en un corto tiempo (hasta quince días), lo que contrasta con las técnicas de injerto que requieren de mayor inversión de tiempo, además, aseguran la calidad fitosanitaria y ventajas ante ciertas características edáficas desfavorables (Das, 2010).

La regeneración de plantas a partir de callos embriogénicos cultivados se ha reportado en periodos largos de subcultivo, por doce meses (Li et al., 2002), 36 meses (Zakizadeh et al., 2008) y hasta 70 meses (Kamo et al., 2005). Sin embargo, la obtención de material vegetal a partir de callos subcultivados puede venir acompañada de variación somaclonal (anormalidades fenotípicas y genotípicas) en plántulas regeneradas ante la continua manipulación de los tejidos in vitro (Zakizadeh, 2008); además, la capacidad embriogénica se reduce debido a la pérdida de totipotencia (Benson, 2000; Jha, 2004).

La proliferación de yemas en rosa es una tarea sencilla, sin embargo, el enraizamiento in vitro es complicado (Salekjalali et al., 2011), debido a que es altamente dependiente del genotipo (Arnold et al., 1995) y la concentración de sales como las Van der Salm (Davoudi et al., 2015) en el medio de cultivo Murashige y Skoog (1962), conocido como MS. Otros factores que afectan el enraizamiento in vitro son la aplicación de bajas temperaturas en condiciones de oscuridad y la auxina utilizada (Pati et al., 2006). Se ha reportado enraizamiento de un promedio de 50\% en medio MS al 50\% de su concentración (Ozel y Arslan, 2006; Ambros et al., 2016), y más del 90\% en MS al 50\% suplementado con $2 \mathrm{mg} / \mathrm{l}$ de ácido indol butírico (IBA) (Salekjalali et al., 2011). Por otro lado, Korban et al. (2006) recomendaron usar MS al 100\%, suplementado con vitaminas MS y $30 \mathrm{~g} / \mathrm{l}$ de sacarosa. 
Las rosas tienen una fuente de genes limitada (Rajapakse et al., 1992; Vainstein y Ben-Mehir, 1994). El cultivo de tejidos permite la transformación genética así como el cultivo de embriones poco viables. El empleo de estas técnicas permite incrementar el material genético de manera artificial, lo que no se logra de manera natural (Abdolmohammadi et al., 2014; Li et al., 2002). Por otra parte, el sistema hidropónico permite mayor productividad, menor consumo de agua (17\% menos requerimiento de agua) y calidad que el cultivo en suelo abierto (Singh, 2017). La técnica de microponía consiste en suministrar los nutrientes en solución mediante diversos materiales empleados como sustrato; es una combinación de hidroponía y aclimatación ex vitro (Nhut et al., 2005; Sallanon et al., 1998; Wang et al., 2012), y puede permitir un mayor desarrollo vegetal en comparación con la aclimatación en medio líquido y sólido (Thien-Nghia et al., 2017). Las principales dificultades de esta técnica son contaminación de las soluciones nutritivas, manejo de $\mathrm{pH}$ (Nhut et al., 2005), y la adquisición de apariencia vidriosa (vitrificación) debido a la alta humedad (Thien-Nghia et al., 2017; Scheneider, 2005; Wang et al., 2012). La alta luminosidad y el alto potencial osmótico reducen la adaptabilidad de las plántulas a condiciones ex vitro (Sallanon et al., 1998).

Para el cultivo de la rosa se requiere de investigación sobre la aclimatación en medio líquido y evaluar la oxigenación, con el fin de evitar la necesidad de una previa aclimatación en sustrato sólido, lo cual supone un menor costo y una directa incorporación en sistema hidropónico. Las plantas obtenidas in vitro no tienen un buen funcionamiento de estomas, por lo tanto, tienen baja asimilación de dióxido de carbono (Sallanon et al., 1998). La consecuente exposición al ambiente debe ser cuidadosa para evitar mermas en las plantaciones.

El humus de lombriz (Eisenia foetida Savigny) también ha sido empleado en diferentes proporciones para la aclimatación de Aloe vera (L.) Burm. F. (Vilchez et al., 2007), Morus alba L. (Salas et al., 2011), Anthurium andreanum Linden ex André (Martin et al., 2003), Tylophora indica (Burm $f$.) Merril (Rani y Rana, 2010) y Saccharum officinarum (L.) (Díaz et al., 2004). Sin embargo, el compost debe tener un alto índice de humedad y materia orgánica para favorecer una buena colonización microbiana y prevenir el ataque de hongos fitopatógenos (Hoitink et al., 1996). El aporte de ácidos húmicos en la solución de riego puede incrementar la translocación de nutrientes a las hojas, y así beneficiar la vida de anaquel de la flor cortada para el caso de cultivo de rosa en hidroponía; además, se incrementa la toma de nutrientes (Dastyaran, 2015). Los sustratos formulados con compostas y otros materiales, son considerados satisfactorios para la aclimatación de rosa micropropagada. Se propone que el uso de vermicomposta beneficie el desarrollo vegetal y permita reducir el uso de la turba de musgo (peat moss), debido a que este recurso se considera limitado en la naturaleza.

Se desconoce la capacidad en la proliferación de raíces de brotes de rosa transgénica proveniente de callos cultivados por dos años en medios de enraizamiento, el efecto de la aplicación del humus de lombriz en diferentes proporciones como parte de sustrato ex vitro para aclimatar y enraizar brotes de rosa transgénica procedente de cultivos de tejido de dos años.

Existe desconocimiento sobre el efecto del sistema flotante hidropónico con y sin oxigenación activa como parte de sustrato ex vitro para una adecuada aclimatación y enraizamiento de brotes de rosa transgénica procedente de cultivos de tejido de dos años.

El objetivo de esta investigación fue evaluar tres medios de enraizamiento in vitro y diferentes sustratos para la aclimatación ex vitro mediante medios sólidos y líquidos de la rosa transgénica.

\section{Materiales y métodos}

\section{Material biológico utilizado}

Se utilizaron brotes de Rosa hybrida transgénica cv. Classy procedentes de callos embriogénicos cultivados por dos años y multiplicados en el medio de cultivo recomendado por Korban et al. (2006). Se eligieron rosas con 
ápices activos, buena apariencia y sin enraizar para dos experimentos separados: (1) enraizamiento in vitro y (2) enraizamiento y aclimatación simultánea ex vitro.

\section{Experimento de enraizamiento in vitro}

El trabajo se realizó de agosto del 2012 a enero del 2013, en las instalaciones del Centro de Investigación y Asistencia en Tecnología y Diseño del Estado de Jalisco, A.C. (CIATEJ), ubicado en la ciudad de Guadalajara, Jalisco, México. Para este experimento, se utilizaron brotes que se cortaron en su base antes de ser establecidos en medio de enraizamiento. Se utilizaron frascos con una longitud de $12 \mathrm{~cm}$ y un diámetro de $4,8 \mathrm{~cm}$ en los que se vertieron $15 \mathrm{ml}$ de medio para enraizamiento. Se eligieron explantes con una longitud promedio de $1,25 \mathrm{~cm} \mathrm{y}$ seis hojas por planta.

Se colocó un explante por frasco, y se incubaron en condiciones de fotoperiodo de $16 \mathrm{~h}$ de luz y $8 \mathrm{~h} \mathrm{de}$ oscuridad, con una intensidad de luz de 1200 luxes y una temperatura de $21^{\circ} \mathrm{C}$ durante tres semanas. Se utilizó el medio basal MS a diferente concentración según los medios empleados por Korban et al. (2006) (K), Ozel y Arslan (2006) (OA) y Salekjalali et al. (2011), los cuales tuvieron como constantes los parámetros de 2,5 g/l de gelrite gellan gum, concentración de 100\% de vitaminas MS y pH de 5,7. Los factores variables de los medios de cultivo fueron la concentración de sales MS (Murashige y Skoog, 1962), sacarosa, ácido indol butírico y carbón activado, los cuales se aplicaron solamente en los tratamientos $\mathrm{K}$ y S, respectivamente (Cuadro 1).

Cuadro 1. Composición de medios de cultivo para enraizamiento in vitro evaluados en Rosa hybrida L. cv. Classy. Guadalajara, México. 2012-2013.

Table 1. Composition of in vitro rooting media evaluated in Rosa hybrida L. cv. Classy. Guadalajara, Mexico. $2012-2013$.

\begin{tabular}{lccc}
\hline & \multicolumn{3}{c}{ Tratamientos de enraizamiento in vitro } \\
\cline { 2 - 4 } Composición de los medios & Korban et al. (2006) (K) & Ozel y Arslan (2006) (OA) & Salekjalali et al. (2012) (S) \\
\hline Medio Murashige y Skoog (1962) & $100 \%$ & $50 \%$ & $50 \%$ \\
Sacarosa & $30 \mathrm{~g} / 1$ & $20 \mathrm{~g} / 1$ & $30 \mathrm{~g} / 1$ \\
Ácido Indol Butírico & - & - & $2 \mathrm{mg} / 1$ \\
Carbón activado & $0,5 \mathrm{~g} / 1$ & - & - \\
\hline
\end{tabular}

Se evaluaron tres tratamientos con cinco repeticiones cada uno, con una planta por repetición y como unidad experimental, con un diseño completamente al azar $(3$ tratamientos $* 5$ repeticiones $* 1$ unidad experimental $(\mathrm{UE})=$ 15 UE). Las variables evaluadas en el experimento de enraizamiento in vitro a los siete, catorce y veintiún días de iniciado el experimento fueron: número de hojas por planta, calidad e intervalo de sobrevivencia de plantas; el porcentaje de enraizamiento se determinó a los treinta días de iniciado el experimento. Se realizó un ANDEVA y una prueba de rango múltiple mediante el método de DMS de Fisher ( $\leq$ 0,05), para lo cual se utilizó el programa Statgraphics para el análisis de los datos.

\section{Experimento de enraizamiento y aclimatación ex vitro}

El experimento de enraizamiento y aclimatación ex vitro estuvo compuesto por siete tratamientos, cinco fueron mezclas de dos sustratos (peat moss $70 \%$ + perlita 30\%) complementados con humus de lombriz en concentraciones ascendentes: $0,25,50,75$ y 100\%. Los dos tratamientos restantes fueron desarrollados con una solución nutritiva líquida como sustrato en los que se evaluó la ausencia (T6) y presencia de oxigenación (T7) (Cuadro 2). 
Cuadro 2. Sustratos evaluados en los experimentos de aclimatación ex vitro de rosa transgénica (Rosa hybrida cv. Classy). Guadalajara, México durante 2012 y 2013.

Table 2. Substrates evaluated in the ex vitro acclimation experiments of transgenic rose (Rosa hybrida cv. Classy). Guadalajara, Mexico during 2012 and 2013.

\begin{tabular}{ccc}
\hline Tratamiento & Sustrato \\
\hline T1 & $0 \%$ Humus & $100 \%($ Peat moss $70 \%+$ Perlita 30\%) \\
T2 & $25 \%$ Humus & $75 \%($ Peat moss $70 \%+$ Perlita $30 \%)$ \\
T3 & $50 \%$ Humus & $50 \%($ Peat moss $70 \%+$ Agrolita $30 \%)$ \\
T4 & $75 \%$ Humus & $25 \%($ Peat moss $70 \%+$ Agrolita $30 \%)$ \\
T5 & $100 \%$ Humus & $0 \%($ Peat moss $70 \%+$ Agrolita $30 \%)$ \\
T6 & Hidropónico & Sin aireación \\
T7 & Hidropónico & Con aireación \\
\hline
\end{tabular}

Las variables evaluadas fueron: número de hojas por planta, calidad de planta e intervalo de sobrevivencia, con lecturas a los 5, 8 y 16 días; la determinación de clorofilas a, b y carotenos totales se realizó a los 8 días de iniciado el experimento; y a los 16 d se evaluó el porcentaje de enraizamiento final. El diseño experimental fue completamente al azar; cada tratamiento tuvo cinco repeticiones, una planta por repetición o como unidad experimental ( 7 tratamientos* 5 repeticiones* 1 unidad experimental $(\mathrm{UE})=7 * 5 * 1=35 \mathrm{UE})$. Se evaluaron los siguientes parámetros: puntajes de calidad de las plantas, número de hojas por planta, porcentaje de enraizamiento y contenido de pigmentos que se describen más adelante. Los datos estadísticos se analizaron mediante un ANDEVA y una prueba de rango múltiple mediante el método de DMS de Fisher $(\mathrm{p} \leq 0,05)$ con ayuda del programa Statgraphics.

\section{Aclimatación y enraizamiento ex vitro en sustrato sólido}

Para el experimento en sustrato se escogieron brotes con una longitud promedio de $1,98 \mathrm{~cm}$ y 4,4 hojas por brote. Para el establecimiento ex vitro, la parte basal de las plantas se desinfectó con una mezcla de los productos Captan Ultra 50 WP (Captan 50\%, Arysta Life Science) y Benommilo (Benomilo 50\%, Provedora Agroindustrial de Sinaloa, S.A. de C.V.), y se colocaron en macetas desinfectadas con el sustrato correspondiente. Para cada tratamiento de mezcla de sustratos, $70 \%$ peat moss $+30 \%$ perlita y humus correspondió una cantidad determinada de agua destilada estéril para regar; a mayor contenido de humus correspondió un menor contenido de agua (Cuadro 3).

Cuadro 3. Cantidades de agua destilada con las que se hidrataron las mezclas de sustrato para el establecimiento ex vitro de rosa transgénica (Rosa hybrida cv. Classy). Guadalajara, México.

Table 3. Quantities of distilled water with which substrate mixtures were hydrated for the ex vitro transgenic rose (Rosa hybrida cv. Classy) establishment. Guadalajara, Mexico.

\begin{tabular}{cccc}
\hline Tratamiento & Humus & Perlita 30\% +Peat Moss 70\% & $\begin{array}{c}\text { Cantidad de agua empleada en 1000 } \\
\mathbf{c m}^{\mathbf{3}} \mathbf{\text { de sustrato }}(\mathbf{m l})\end{array}$ \\
\hline 1 & $0 \%$ & $100 \%$ & 290,91 \\
2 & $25 \%$ & $75 \%$ & 183,95 \\
3 & $50 \%$ & $50 \%$ & 162,57 \\
4 & $75 \%$ & $25 \%$ & 141,18 \\
5 & $100 \%$ & $0 \%$ & 141,18 \\
\hline
\end{tabular}




\section{Aclimatación y enraizamiento ex vitro en hidroponía}

Para el experimento de hidroponía se usó una metodología similar a la descrita por Scheneider (2005). Se seleccionaron brotes con una longitud promedio de $2,1 \mathrm{~cm}$ y cuatro hojas por brote, a las que se aplicó polvo enraizador comercial (Raizone) que contenía ácido indol-3-butírico a 1500 ppm. Como base nutritiva se utilizó la solución descrita por Hoagland y Arnon (1950). Se utilizaron recipientes de plástico para establecer las plantas en aclimatación en hidroponía, con una longitud de $6,5 \mathrm{~cm}$, un radio superior de $11 \mathrm{~cm}$, radio inferior de $9 \mathrm{~cm}$ y capacidad de $550 \mathrm{~cm}^{3}$. Cada envase contenía $460 \mathrm{ml}$ de solución nutritiva con una bolsa de plástico transparente y un brote. Se evaluó la presencia de agitación activa de la solución nutritiva y la ausencia de esta. A los recipientes para el primer experimento se les practicó una perforación para introducir una manguera, que se conectó a una bomba de acuario para proveer la aireación.

\section{Variables evaluadas}

\section{Puntajes de calidad de las plantas}

Se eligió una metodología para evaluar el desarrollo de las plantas en los experimentos de enraizamiento in vitro y aclimatación, previamente empleada por Scheneider (2005), para así registrar el desempeño de los experimentos de enraizamiento in vitro y aclimatación ex vitro de brotes transgénicos de Rosa hybrida cv. Classy.

Los parámetros cuantificados fueron mortalidad de hojas, calidad del follaje y desarrollo general de los explantes como se indica en el Cuadro 4. El rango de mortalidad se calculó en base al total de repeticiones y plantas sobrevivientes.

Número de hojas por planta y porcentaje de enraizamiento

Se determinó una media de número de hojas por planta, mediante un conteo de hojas desarrolladas completamente (con sus tres foliolos desarrollados) en cada planta. El porcentaje de enraizamiento se determinó mediante el conteo de plántulas enraizadas entre el número total de plantas.

\section{Contenido de pigmentos}

La metodología utilizada para cuantificar el contenido de clorofilas a, b y carotenos en los brotes de rosas aclimatadas ex vitro fue la descrita por Dere et al. (1998), con las modificaciones realizadas por Rout et al. (1998). Los resultados del contenido de clorofilas fueron comparados a través de un ANDEVA y una prueba de rango múltiple mediante el método de DMS de Fisher $(\mathrm{p} \leq 0,05)$, para lo cual se utilizó el programa Statgraphics.

\section{Resultados}

\section{Enraizamiento in vitro}

\section{Puntajes de calidad de planta}

Los resultados de la evaluación de la calidad de la planta a los siete días posteriores de su traspaso a los sustratos o medios de enraizamiento (Cuadro 1), indicaron que los tratamientos $\mathrm{K}$ y OA obtuvieron un puntaje 
promedio de 7 de un máximo de 9 (Cuadro 4). No obstante, el desarrollo de las plantas se vio afectado en los días siguientes (decremento de puntaje 7 a 5 a los catorce días en los tratamientos $\mathrm{K}$ y OA, y de 5 a 3 en el tratamiento S), y se observó estable a los veintiún días en los medios K y OA.

Cuadro 4. Puntaje de calidad de la plántula de rosa transgénica (Rosa hybrida cv. Classy). Guadalajara, México. $2012-2013$.

Table 4. Quality score of transgenic rose (Rosa hybrida cv. Classy) seedlings. Guadalajara, Mexico. 2012-2013.

\begin{tabular}{|c|c|c|c|}
\hline $\begin{array}{l}\text { Puntaje } \\
\text { de calidad }\end{array}$ & Hojas muertas & $\begin{array}{l}\text { Calidad promedio de } \\
\text { follaje }\end{array}$ & $\begin{array}{l}\text { Desarrollo general de } \\
\text { la plántula }\end{array}$ \\
\hline 1 & $\begin{array}{c}\text { Planta muy débil o } \\
\text { muerta }\end{array}$ & Hojas sin funcionar & $\begin{array}{c}\text { Síntomas de } \\
\text { Hiperhidratación }\end{array}$ \\
\hline 3 & Muchas hojas muertas & $\begin{array}{l}\text { Presencia de hojas } \\
\text { amarillentas }\end{array}$ & $\begin{array}{c}\text { Síntomas de } \\
\text { Hiperhidratación }\end{array}$ \\
\hline 5 & Algunas hojas muertas & $\begin{array}{c}\text { Presencia de hojas } \\
\text { verdes }\end{array}$ & Crecimiento reducido \\
\hline 7 & Pocas hojas muertas & $\begin{array}{l}\text { Presencia de hojas verde } \\
\text { oscuro }\end{array}$ & $\begin{array}{l}\text { Buen desarrollo de } \\
\text { yemas }\end{array}$ \\
\hline 9 & $\begin{array}{l}\text { Casi ningúna hoja } \\
\text { muerta }\end{array}$ & $\begin{array}{l}\text { Presencia de hojas verde } \\
\text { oscuro }\end{array}$ & $\begin{array}{l}\text { Desarrollo excelente de } \\
\text { brotes }\end{array}$ \\
\hline
\end{tabular}

\section{Número de hojas por planta}

Los resultados obtenidos a los siete días indicaron que el tratamiento (K) tuvo un promedio de 7,4 hojas por planta, mientras que el tratamiento OA obtuvo el mayor promedio alcanzando ( 8,8 hojas por planta) (Cuadro 1). A los veintiún días todas las plantas de los tres tratamientos presentaron una disminución en el número de hojas, a la mitad de la observada a los siete días.

\section{Porcentaje de enraizamiento}

Solo el 60\% de las plantas del medio (K) enraizaron a los treinta días, mientras que, en los demás tratamientos se manifestó mortalidad en las plantas, sin desarrollo alguno de raíz. El tercer tratamiento (S) presentó desarrollo de callosidad en la base de los explantes, pero nula presencia de raíces. 


\section{Enraizamiento y aclimatación ex vitro}

\section{Puntajes de calidad de planta}

A los cuatro días, los tratamientos T1, T4 y T6 alcanzaron 5 puntos en promedio, lo que indica mayor follaje verde que hojas amarillentas (Cuadro 4). El resto de los tratamientos presentaron puntajes inferiores: T2 con 3 puntos, lo que indicó un follaje relativamente sano con pocas manchas amarillentas y crecimiento reducido. Por otro lado, los tratamientos T7 y T5, a pesar de que también obtuvieron 3 puntos, presentaron menor desarrollo y muchas hojas muertas y amarillentas (Cuadro 5).

Cuadro 5. Puntajes de calidad de plantas de rosa transgénica (Rosa hybrida cv. Classy), en los tratamientos de sustrato en aclimatación ex vitro, evaluados hasta los dieciséis días de aclimatación. Guadalajara, México, durante 2012 y 2013.

Table 5. Quality score of transgenic rose (Rosa hybrida cv. Classy) plants, in the substrate treatments in ex vitro acclimatization, evaluated throughout sixteen days of acclimatization. Guadalajara, Mexico, during the years 2012 and 2013.

\begin{tabular}{ccccc}
\hline Tratamiento & 4 días & 8 días & 12 días & 16 días \\
\hline T 1: 0\% humus & 5 & 5 & 3 & 3 \\
T 2: $25 \%$ humus & 3 & 3 & 3 & 3 \\
T 3: 50\% humus & 1 & 1 & 1 & 1 \\
T 4: $75 \%$ humus & 5 & 3 & 1 & 1 \\
T 5: $100 \%$ humus & 3 & 1 & 1 & 1 \\
\hline
\end{tabular}

Número de hojas por planta

A los cuatro días de establecimiento, los tratamientos con menor contenido de humus (T1 y T2) mantuvieron mayor follaje que los demás sustratos evaluados a los dieciséis días de establecimiento. Sobre el número de hojas por planta, los más altos promedios se obtuvieron en los tratamientos T1, T2 y T6, con 1,6, 0,8 y 0,6 hojas por planta, respectivamente, al término del experimento

\section{Rango de sobrevivencia de plantas}

Los tratamientos que mejor proporción de sobrevivencia al paso de los días mostraron T1, T2 y T6, en los cuales se detectaron el 60\% en T1 y T2, y el $40 \%$ para $\mathrm{T} 6$ de las plantas vivas a los dieciséis días. Los tratamientos con menor cantidad de plantas vivas fueron T3, T5, T4 y T7, los cuales no presentaron plantas sobrevivientes a los dieciséis días (Figura 1).

\section{Contenido de clorofilas $a, b$ y carotenos}

El contenido promedio por tratamiento de clorofila a fluctuó entre $201,2 \mu \mathrm{g} / \mathrm{g}$ (T5) y $544,8 \mu \mathrm{g} / \mathrm{g}$ de peso fresco (T2). Se encontraron diferencias significativas entre los tratamientos, T2 obtuvo el mayor contenido a, seguido de T1 $(435,54 \mu \mathrm{g} / \mathrm{g})$. Entre los tratamientos T3 y T6 y T7 no presentaron diferencias significativas, los cuales 


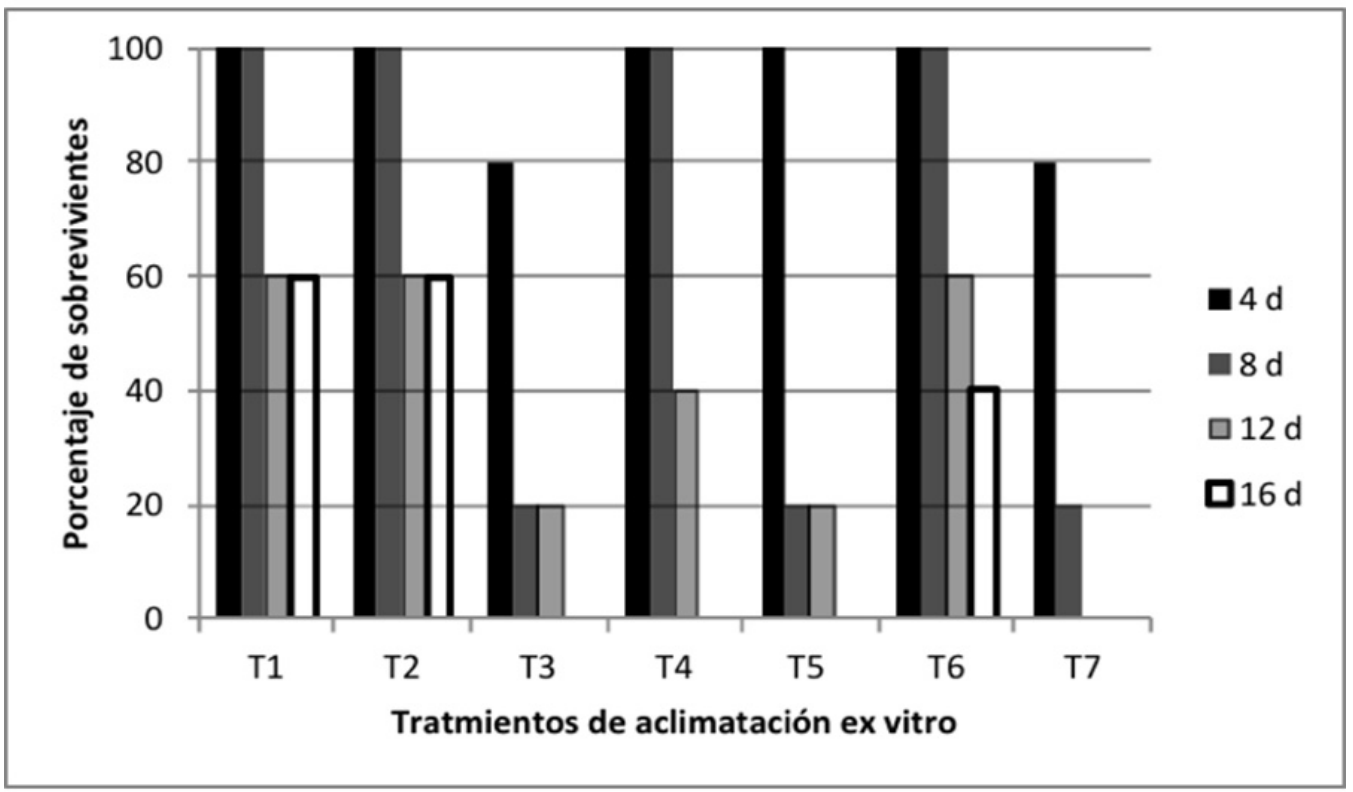

Figura 1. Sobrevivencia de plantas provenientes de cultivo in vitro en diferentes tratamientos con sustrato en condiciones ex vitro de rosa (Rosa hybrida) transgénica cv. Classy. Cada tratamiento contó con cinco plantas evaluadas. Guadalajara, México. 2012-2013.

Tratamientos: h: humus (T1: 0\%, T2: 25\%, T3: 50\%, T4: 75\% y T5: 100\%), T6: hidroponía sin oxigenación, T7: hidroponía con oxigenación.

Figure 1. Survival rate of plants coming from in vitro culture in different treatments with substrates in ex vitro conditions of transgenic rose (Rosa hybrida cv. Classy). Each treatment contained five plants evaluated. Guadalajara, Mexico. 2012-2013. Treatments: h: humus (T1: 0\%, T2: 25\%, T3: 50\%, T4: 75\% and T5: 100\%), T6: hydroponics without oxygenation, T7: hydroponics with oxygenation..

tuvieron 309,4, 341,91 y 358,12 $\mu \mathrm{g} / \mathrm{g}$, respectivamente. Los tratamientos con mayor contenido de humus (T4 y T5) alcanzaron un menor contenido de clorofila a (231,5 y 201,22 $\mu \mathrm{g} / \mathrm{g}$ ) (Figura 2).

En el caso de la clorofila b los valores variaron entre $377 \mu \mathrm{g} / \mathrm{g}$ (T5) y 1042,02 $\mu \mathrm{g} / \mathrm{g}$ de peso fresco de hoja (T2). Se encontraron diferencias significativas entre los tratamientos, T2 obtuvo un mayor contenido. El análisis estadístico separó resultados en cinco grupos, en los cuales el tratamiento con 25\% de humus (T2), representó el primer grupo, mientras que los T4 y T5 que tuvieron mayor concentración de tratamiento de humus representaron el grupo con menor concentración de clorofila b (con 423,5 y 377,04 $\mu \mathrm{g} / \mathrm{g}$, respectivamente). Los tratamientos con aclimatación en hidroponía representaron el grupo cuatro (T6 y T7) con un contenido moderado concentración de clorofila b $(654,95$ y $693,71 \mu \mathrm{g} / \mathrm{g})$.

Los contenidos de carotenos mostrados fueron: $71,54 \mathrm{mg} / \mathrm{g}$ en T2, seguido de T1 con $56,97 \mathrm{mg} / \mathrm{g}$ y T6 con $47 \mathrm{mg} / \mathrm{g}$. El análisis estadístico separo resultados en cinco grupos en los cuales el primero estuvo conformado por T2, seguido de T1 y T6 en el segundo y tercer grupo, respectivamente. T7 quedo agrupado dentro del tercer grupo según el análisis estadístico con $46 \mathrm{mg} / \mathrm{g}$, mientras que el quinto y último lugar, lo ocuparon T4 y T5 con 30 y 25 $\mathrm{mg} / \mathrm{g}$ de peso freso de carotenos. 

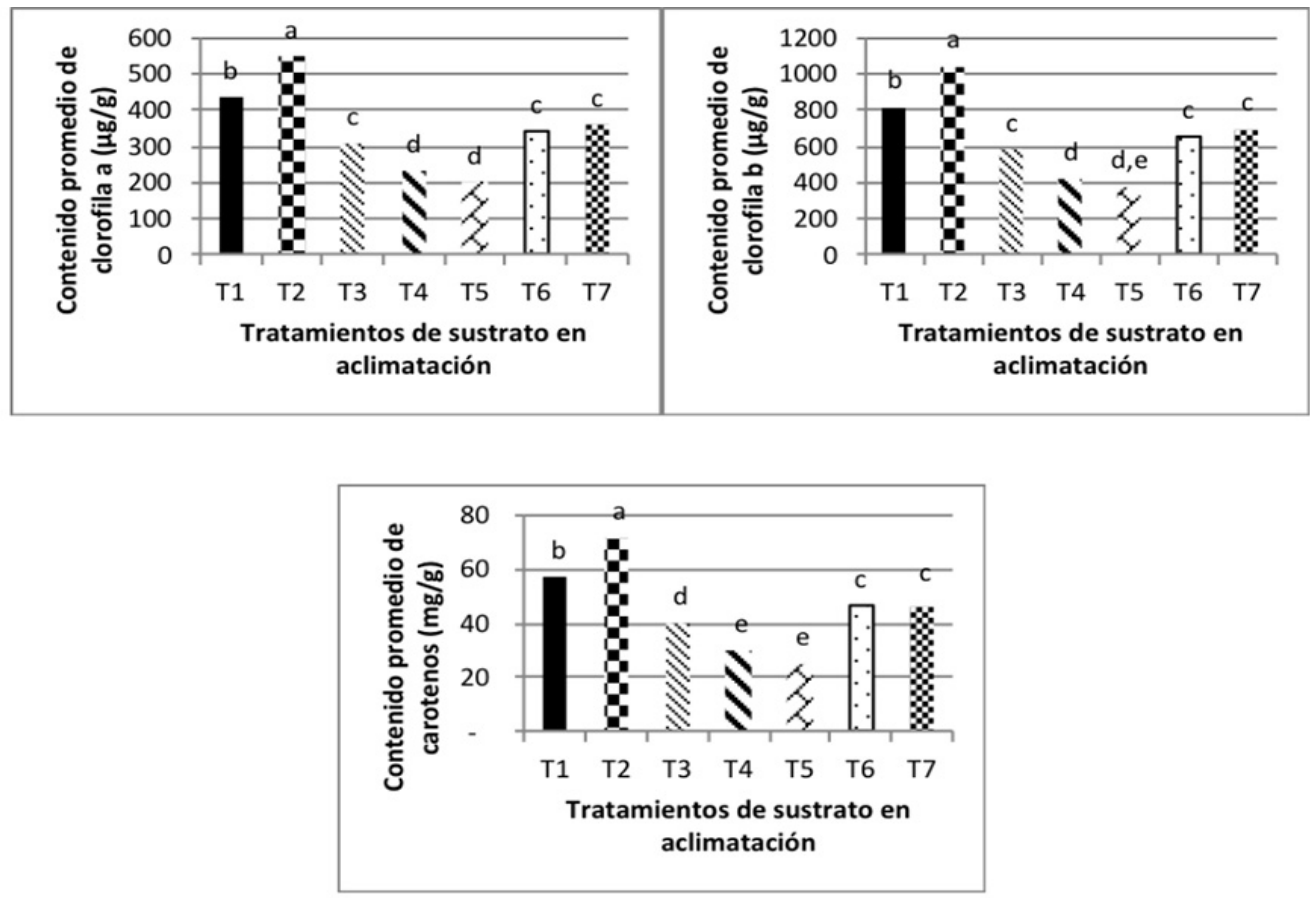

Figura 2. Contenido promedio de clorofila a y b y carotenos en los tratamientos de aclimatación y sustratos con humus en ocho días de establecimiento con de rosa (Rosa hybrida) transgénica cv. Classy. Guadalajara, México. 2012-2013.

Medias con letras iguales fueron estadísticamente similares según prueba de diferencia significativa mínima de Fisher, 0,05. Cada tratamiento contó con cinco plantas evaluadas. Tratamientos: h: humus (T1: 0\%, T2: 25\%, T3: 50\%, T4: 75\% y T5: 100\%), T6: hidroponía sin oxigenación, T7: hidroponía con oxigenación.

Figure 2. Averages of Chlorophyll a and $\mathrm{b}$ and carotenes in the ex vitro acclimatization treatments and in the humus substrates with eight days of establishment with transgenic rose (Rosa hybrida cv. Classy). Guadalajara, Mexico. 2012-2013.

Medias with the same letters were statistically similar according to Fisher's minimum significant difference test, 0.05 . Each treatment contained five plant evaluated. Treatments: h: humus (T1: 0\%, T2: 25\%, T3: 50\%, T4: 75\% and T5: 100\%), T6: hydroponics without oxygenation, T7: hydroponics with oxygenation.

\section{Porcentaje de enraizamiento}

En T1 el 20\% de las rosas desarrollaron raíz, en cambio en las plantas sobrevivientes de T2 y T6 no se detectó producción de raíz.

\section{Discusión}

\section{Enraizamiento in vitro}

\section{Puntajes de calidad de planta}

Los tratamientos de enraizamiento in vitro $\mathrm{K}$ y OA (Cuadro 1), obtuvieron los puntajes de calidades superiores de los tratamientos de enraizamiento in vitro (con tres y cinco), y resultaron superiores a los descritos por 
Scheneider (2005), al evaluar plántulas de Rosa spp en un periodo de cuatro a siete días después de establecerlas en medio sólido para enrizamiento enriquecido con 0,1 o $0,5 \mathrm{mg} / \mathrm{l}$ de AIB con puntajes de seis y tres, respectivamente.

\section{Número de hojas por planta}

Los tratamientos no mostraron diferencias significativas entre sí $(\mathrm{p} \leq 0,05)$ durante las dos primeras evaluaciones de número de hojas por planta (7 y 14 días, entre 7,4 y 8,8 hojas/planta) y después procedieron a tener un menor número de hojas, lo cual difiere a lo reportado por Scheneider (2005), quien mencionó que las plántulas presentaron una tendencia a aumentar su follaje. El número esperado de hojas fue mayor al que se había presentado a los primeros catorce días durante la tercera medición (que se realizó veintiún días después del enraizamiento in vitro).

\section{Porcentaje de enraizamiento}

Mejor sobrevivencia en condiciones ambientales y mayor porcentaje de plántulas enraizadas (90\%) con medio MS al 50\% generó su concentración y $2 \mathrm{mg} / \mathrm{l}$ de IBA, fueron obtenidos por Salekjalali et al. (2011); sin embargo, en el presente trabajo se observó una alta defoliación, bajo porcentaje de enraizamiento y desarrollo de callosidad. Dicho fenómeno afectó la absorción de agua y nutrientes (Davoudi et al., 2015), por lo tanto, inhibió el crecimiento de los brotes y una posible emisión de etileno en los tejidos.

Los explantes de cinco genotipos diferentes de rosa presentaron un menor porcentaje de enraizamiento a concentraciones en el medio mayores a $0,8 \mathrm{mg} / \mathrm{l}$ de AIB en una investigación realizado por Arnold et al. (1995), sin embargo, en el presente trabajo se utilizó una concentración de $2 \mathrm{mg} / 1$, mientras que Schneider (2005) había observado desarrollo de callosidad a una concentración de $0,5 \mathrm{mg} / \mathrm{l}$ de IBA. Se ha observado un mayor porcentaje de explantes de rosa enraizados in vitro (cercanos al 90\%) con la concentración 100\% de sales MS en trabajos previos con bajas concentraciones de auxina (menores a $1 \mathrm{mg} / \mathrm{ml}$ ) (Arnold et al., 1995). En otros estudios se encontraron enraizamientos de entre 90 y $83 \%$ en explantes de dos diferentes cultivares a una concentración de $50 \%$ de medio MS y 0,5 mg/l de AIB (Baig et al., 2011), y de 90\% en un medio con un $25 \%$ de concentrado de sales MS y 0,25 mg/l de AIB en cv. Landora (Das, 2010).

\section{Enraizamiento y aclimatación ex vitro}

\section{Puntajes de calidad de planta}

Los tratamientos T1, T6 y T4 alcanzaron el mayor puntaje de calidad de planta, lo cual contrasta con los resultados de las evaluaciones desarrolladas por Díaz et al. (2004), quienes a distintas concentraciones de humus $(0,20,40,60,80$ y 100\%) en la aclimatación ex vitro de Saccharum spp., observaron mejor desarrollo vegetal y menor incidencia de infecciones en ausencia de humus, en cambio, la longitud de raíces fue beneficiada a medida que la cantidad de vermicomposta aumentaba.

\section{Número de hojas por planta}

Los tratamientos T1, T2 y T6 mantuvieron mayor follaje que los otros cuatro tratamientos, de manera similar a los puntajes de calidad de planta, similar a lo obtenido por Schneider (2005), quien observó un mayor contenido de follaje a mayor concentración de turba de musgo (peat moss). Los tratamientos con mayor cantidad de humus (T4 y T5) no presentaron follaje alguno a dieciséis días de iniciado el experimento, contrario a los resultados de otras 
investigaciones donde los tratamientos con vermicomposta permitieron la generación de mayor número de hojas por planta en Aloe vera (Vilchez et al., 2007) y en Tylophora indica (Rani y Rana, 2010).

\section{Rango de sobrevivencia de plantas}

Los resultados de sobrevivencia estimada en un $60 \%$ para los $\mathrm{T} 1$ y $\mathrm{T} 2$, coincidieron con lo reportado por Zakizadeh et al. (2008), quienes aclimataron en turba plántulas de rosa procedentes de callos cultivados por 36 meses. Por otro lado, se han encontrado distintos índices de sobrevivencia con el uso de compostas en la aclimatación de rosa que varían entre 60\% (Das, 2010) y 80\% (Xing et al., 2009), lo cual no sucedió a los dieciséis días después del establecimiento del presente experimento. En la aclimatación de plántulas de Gypsophila paniculatta en hidroponía con el empleo de sesenta brotes por unidad experimental, se reportó una sobrevivencia del $80 \%$ a los treinta días después del establecimiento (Wang et al., 2012). A diferencia de este estudio, el tratamiento 6 de hidroponía del presente experimento mostró un $40 \%$ de sobrevivientes a los dieciséis días; además se utilizó un brote por unidad experimental.

\section{Contenido de clorofilas a, $b$ y carotenos}

Los contenidos de clorofila fueron mayores en sustrato con peat moss $70 \%+$ perlita $30 \%(0,436 \mathrm{mg} / \mathrm{g}$ en peso fresco en clorofila a, y $0,816 \mathrm{mg} / \mathrm{g}$ en peso fresco en clorofila b) que en medio líquido sin oxigenación (clorofila a $0,341 \mathrm{mg} / \mathrm{g}$, clorofila b a $0,654 \mathrm{mg} / \mathrm{g}$ en peso fresco), los cuales fueron similares a los resultados reportados por Schneider (2005) en Rosa sp. Los cocientes de clorofila a/b fueron muy similares en todos los tratamientos, valores considerados muy bajos, por lo que, las plantas presentaron un estrés (Barber, 1994; Shaw, 1995). Es posible que la adaptación de las plantas lleve mayor tiempo, debido a que el control estomático es nulo (Sallanon et al., 1991). Se reportan valores de cociente clorofila a/b mayores a 2 para plántulas micropropagadas de vid bajo condiciones de baja intensidad de luz (2960 luxes) y de alrededor de 4 en alta intensidad de luz (6660 luxes) (Amancio et al., 1999).

Según un estudio, la actividad fotosintética (medición de fluorescencia de clorofila) fue menor (hasta en un $100 \%)$ en condiciones de alto potencial osmótico (-0,3 MPa), comparado con el testigo (-0,05 MPa) a partir de una intensidad de 7400 luxes (Sallanon et al., 1998). En el presente estudio, se utilizó una intensidad de 1200 luxes y la solución de Steiner, lo cual resultó menor a lo reportado.

\section{Porcentaje de enraizamiento}

El porcentaje de plantas enraizadas fue muy bajo, solo el 20\% de las plantas enraizaron en T1 (0\% humus), lo cual puede relacionarse con el hecho de que se cultivó con varios medios. Las plantas obtenidas por regeneración de callos de distintos periodos de tiempo, por lo general, se aclimatan y enraizan exitosamente en sustratos con turba (Murali et al., 1996; Li et al., 2002; Zakizadeh et al., 2008), con porcentajes de enraizamiento mayores al 90\%; no obstante, el enraizamiento puede no presentarse (Rout et al., 1991) o conseguirse después de hacer cultivo con al menos dos medios diferentes (Jabbarzadeh y Kosh-Khui, 2005).

\section{Conclusión}

Los resultados obtenidos permitieron elegir el medio más apropiado de enraizamiento in vitro, aclimatación ex vitro y la influencia de la aireación en la solución nutritiva en el proceso de aclimatación. Con la ausencia de oxigenación activa en el tratamiento hidropónico (T6) se registró mayor promedio de hojas y mayor sobrevivencia 
que con la presencia de aireación (T7), sin embargo, en ambos tratamientos no se encontró enraizamiento. En contraste con la teoría planteada al inicio, la aireación activa no influyó positivamente en la producción de raíz en un sistema hidropónico de raíz flotante.

\section{Agradecimientos}

Los autores agradecen al Consejo Nacional de Ciencia y Tecnología (CONACYT) y al Fondo Mixto del Gobierno del Estado de Morelos, por el financiamiento de este proyecto.

\section{Literatura citada}

Abdolmohammadi, M., M.J. Kermani, H. Zakizadeh, and Y. Hamidoghli. 2014. In vitro embryo germination and interploidy hybridization of rose (Rosa sp). Euphytica 198:255-264. doi:10:1007/s10681-014-1098-0

Amancio, S., J.P. Rebordao, and M.M. Chaves. 1999. Improvement of acclimatization of micropropagated grapevine: photosynthetic competence and carbon allocation. Plant Cell, Tiss. Organ Cult. 58:31-37. doi:10.1023/A:100632312

Ambros, E.V., O.Y. Vasilyeva, and T.I. Novikova. 2016. Effects of in vitro propagation on ontogeny of Rosa canina L. micropropagated plants as a promising rootstock for ornamental roses. Plant Cell Biotechnol. Mol. Biol. 17:72-78.

Arnold, N.P., M.R. Binns, D.C. Cloutier, N.N. Barthakur, and R. Pellerin. 1995. Auxins, salts concentrations, and their interactions during in vitro rooting of winter-hardy and hybrid tea roses. HortScience 30:1436-1440.

Baig, M.M.Q., I.A. Hafiz, A. Hussain, T. Ahmad, and N.A. Abbasi. 2011. An efficient protocol for in vitro propagation of Rosa gruss an teplitz and Rosa centifolia. Afr. J. Biotechnol. 10:4564-4573. doi:10.5897/AJB10.2051

Barber, J. 1994. Molecular basis of the vulnerability of photosystem II to light. Aust. J. Plant Physiol. 22:201-208. doi:10.1071/ PP9950201

Benson, E.E. 2000. Special Symposium: In vitro plant recalcitrance do free radicals have a role in plant tissue culture recalcitrance. In vitro Cell. Dev. Biol. Plant 36:163-170. doi:10.1007/s11627-000-0032-4

Cárdenas-Navarro, R., y L. López-Pérez. 2011. Propagación vegetativa de rosa: efecto del sustrato, luminosidad y permanencia de la hoja. Sci. Agropecu. 2:203-211. doi:10.17268/sci.agropecu.2011.04.02

Das, P. 2010. Mass cloning of rose and mussaenda, popular garden plants, via somatic embryogenesis. Hort. Sci. 37:70-78.

Dastyaran, M. 2015. Effect of humic acid and exogenous putrescine on vase life and leaf macro elements status of hydroponic cultured rose (Rosa hybrid cv. "Dolce vita"). Agric. Commun. 3(1):43-49.

Davoudi, M., L. Samiei, A. Tehranifar, and M. Shoor. 2015. The effect of medium and plant growth regulators on micropropagation of Dog rose (Rosa canina L.). J. Plant Mol. Breed. 3:61-71.

Dere, S., T. Günes, and R. Sivaci. 1998. Spectrophotometric determination of Chlorophyll- A, B and total carotenoid contents of some alga especies using different solvents. Tr. J. Bot. 22:13-17.

Díaz, L.P., L.F. Medina, J. Latife, P.A. Digonzelli, y S.B. Sosa. 2004. Aclimatación de plantas micropropagadas de caña de azúcar utilizando el humus de lombriz. RIA 33:115-128.

Domínguez-Serrano, D., R. García-Velasco, M.E. Mora-Herrera, M. L. Salgado-Siclan, y J.G. González-Díaz. 2016. La cenicilla del rosal (Podosphaera pannosa). Agrociencia 50:901-917. 
Hoagland, D.R., and D.I. Arnon. 1950. The water-culture method for growing plants without soil. Calif. Agric. Exp. Sta. Circ. $347: 1-32$.

Hoitink, H.A.J., A.G. Stone, and M.E. Grebus. 1996. Suppression of plant disease by compost. In: M. de-Bertoldi, editor, The science of composting. Blackie Academic \& Profesional, Londres, GBR. p. 373-381.

Jabbarzadeh, Z., and M. Khosh-Khui. 2005. Factors effecting tissue culture of Damask rose (Rosa damascene Mill.). Sci. Hort. 105: 475-482. doi:10.1016/j.scienta.2005.02.014

Jha, R. 2004. Role of in vitro propagation in the improvement of rose cultivars. Agric. Rev. 25:100-115.

Kamo, K., B. Jones, J. Bolar, and F. Smith. 2005. Regeneration from long-term embrygenic callus of the Rosa hybrid cultivar Kardinal. In vitro Cell. Dev. Biol. Plant 41:32-36. doi:10.1079/IVP2004599

Korban, S.S., K. Gasic, and X. Li. 2006. Rose (Rosa hybrida L.). In: K. Wang, editor, Methods in molecular biology, Agrobacterium protocols, 2/3. Humana Press Inc., Totowa, NJ, USA. p. 351-359.

Li, X., S.F. Krasnyanski, and S.S. Korban. 2002. Somatic embryogenesis, secondary somatic embryogenesis, and shoot organogenesis in Rosa. J. Plant Physiol. 159:313-319. doi:10.1078/0176-1617-00688

Martin, K.P., D. Joseph, J. Madassery, and V.J. Philip. 2003. Direct shoot regenaration from lamina explants of two commercial cut flowers cultivars of Anthurium andraeanum Hort. In vitro Cell. Dev. Biol. Plant 39:500-504. doi:10.1079/IVP2003460

Murali, S., D. Sreedhar, and T.S. Lokeswari. 1996. Regeneration through somatic embryogenesis from peatl-derived calli of Rosa hybrid L. cv Arizona (hybrid tea). Euphytica 91:271-275. doi:10.1007/BF00033087

Murashige, T., and F. Skoog. 1962. A revised medium for rapid growth and bioassays with tobacco tissue culture. Physiol. Plant 15:473-497. doi:10.1111/j.1399-3054.1962.tb08052.x

Nhut, D.T., N.T. Don, T.T.T. An, T.P.T. Van, N.H. Vun, P.X. Huyen, and D.V. Khiem. 2005. Microponic and hydroponic techniques in disease-free chrysanthemum (Chrysanthemum sp.) production. J. Appl. Hort. 7(2):67-71.

Ozel, C.A., and O. Arslan. 2006. Efficient micropropagation of English shrub rose Heritage under in vitro conditions. Int. J. Agri. Biol. 8:626-629.

Pati, P.K., S.P. Rath, M. Sharma, A. Sood, and P.S. Ahuja. 2006. In vitro propagation of rose-a review. Biotechnol. Adv. 24:94114. doi:10.1016/j.biotechadv.2005.07.001

Rajapakse, S., M. Hubbard, J.W. Kelly, A.G. Abbott, and R.E. Ballard. 1992. Identification of rose cultivars by restriction fragment length polymorphism. Sci. Hort. 52:237-245. doi:10.1016/0304-4238(92)90024-7

Rani, S., and J.S. Rana. 2010. In vitro propagation of Tylophora indica influence of explanting season, growth regulator synergy, culture passage and planting substrate. J. Am. Sci. 6:385-393.

Rout, G.R., B.K. Debata, and P. Das. 1991. Somatic embryogenesis in callus cultures of Rosa hybrid L. cv. Landora. Plant Cell, Tiss. Organ Cult. 27: 65-69. doi:10.1007/BF00048208

Rout, N.P., S.B. Tripathi, and B.P. Shaw. 1998. Effect of salinity on chlorophyll and proline contents in three aquatic macrophytes. Biol. Plant. 40:453-458. doi:10.1023/A:100118650

Salas, J.E., D. Agramonte, F. Jiménez-Terry, M. Pérez, R. Collado, R. Barbón, M. La-O, M. De-Feria, y M. Chávez. 2011. Propagación de plantas de Morus alba var. Criolla con el uso de sistemas de inmersión temporal. Biotecnol. Veg. 11:7788.

Salekjalali, M., B. Jafari, and A. Tarinejad. 2011. In vitro multiplication of rose (Rosa hybrid cv. Baccara). American-Eurasian J. Agric. Environ. Sci. 11:111-116. 
Sallanon, H., M. Berger, C. Genoud, and A. Coudret.1998. Water Stress and photoinhibition in acclimatization of Rosa hybrid plantlets. In vitro Cell. Dev. Biol. Plant 34:169-172. doi:10.1007/BF02822783

Schneider, F. 2005. Effect of different cultural conditions on micropropagartion of rose (Rosa sp. L.) and globe artichoke (Cynara scolymus L.). Dr. Diss., Technische Universität Müncehn, GER.

Shaw, B.P. 1995. Changes in the levels of photosynthetic pigments in Phaseolus aurerus Roxb. exposed to Hg and Cd at two stages of development: a comparative study. Bull. Environ. Contam. Toxicol. 55:574-580.

Singh, B. 2017. Hydroponic culture as screening technique for abiotic stresses. In: V. Paul et al., editors, Manual of ICAR sponsored training programme for technical staff of ICAR institutes on physiological techniques to analyze the impact of climate change on crop plants. ICAR, New Delhi, IND. p. 115-122.

Thien-Nghia, L., H. Thanh-Tung, N. Phuc-Huy, V. Quoc-Luan, and D. Tan-Nhut. 2017. The effects of silver nanoparticles on growth of Chrysanthemum morifolium Ramat. cv. "Jimba" in different cultural systems. Vietnam J. Sci. Technol. 55:503514. doi:10.15625/2525-2518/55/4/9322

Vainstein, A., and H. Ben-Meir. 1994. DNA fingerprint analysis of roses. J. Am. Soc. Hort. Sci. 119:1099-1103.

Vilchez, J., E. Ramírez, M. Villasmil, N. Albany, S. León de Sierralta, y M. Molina. 2007. Aclimatización de vitroplantas de zábila (Aloe vera L.) Burm. f): efectos del sustrato. Rev. Fac. Agron. (LUZ) 24:57-61.

Wang, S.M., X.C. Piao, S.Y. Park, and M.L. Lian. 2012. Improved micropropagation of Gypsophila paniculata with bioreactor and factors affecting ex vitro rooting in microponic system. In vitro Cell. Dev. Biol. Plant 49: 70-78. doi:10.1007/s11627012-9464-x

Xing, W., M. Bao, H. Qin, and G. Ning. 2009. Micropropagation of Rosa rugosa through axillary shoot proliferation. Acta Biol. Cracov. Bot. 52:69-75. doi:10.2478/v10182-010-0025-5

Zakizadeh, H. 2008. Somatic embryogenesis, transformation with PSAG12-IPT gene for leaf senescence retardation, and characterization of SERK genes in miniature potted rose (Rosa hybrid "Linda"). Ph.D. Thesis, University of Copenhagen, DEN.

Zakizadeh, H., T. Debener, S. Sriskandarajah, S. Frello, and M. Serek. 2008. Regeneration of mianiature potted rose (Rosa hybrida L.) via somatic embryogenesis. Europ. J. Hort. Sci. 73:111-117. 